\title{
The Role of Remineralizing Agents Used in Dentistry: An Update Then and Now
}

\author{
Dr. Shakir Hussain Rather ${ }^{1 *}$, Dr. Sajedabanu Kazi ${ }^{2}$, Dr. Safikabanu Kazi ${ }^{3}$ \\ ${ }^{1}$ Department of Pediatric \& Preventive Dentistry \\ ${ }^{2,3}$ Private Practitioner
}

DOI: $10.36348 /$ sjbr.2020.v05i07.003

| Received: 12.07.2020 | Accepted: 20.07.2020 | Published: 21.07.2020

*Corresponding author: Dr. Shakir Hussain Rather

\section{Abstract}

Among oral diseases dental caries is a highly prevalent multifactorial disease and has been a major public health problem for many centuries. Several remineralizing agents helps in remineralization to prevent disease progression, and to improve form and function of the teeth. Remineralization is the process of depositing calcium and phosphate ions into crystal voids in demineralized enamel, thus producing net mineral gain. The present article reviews about the various agents that enhance and promote remineralization of tooth structure and their implementation into clinical practice.

Keywords: Dental Caries, Remineralizing agents, Demineralization, non-invasive treatment.

Copyright @ 2020: This is an open-access article distributed under the terms of the Creative Commons Attribution license which permits unrestricted use, distribution, and reproduction in any medium for non-commercial use (NonCommercial, or CC-BY-NC) provided the original author and source are credited.

\section{INTRODUCTION}

Dental Caries is the most prevalent chronic diseases worldwide, and a burden to health-care services [1]. The proportion among demineralization and remineralization is critical, deciding the hardness and quality of tooth structure. Demineralization results from a complex chemistry between bacteria, diet, and salivary components [2]. A drop in $\mathrm{pH}$ of oral cavity results in demineralization which if continued leads to loss of minerals from tooth structure resulting in dental caries [3]. Remineralization is defined as the process whereby calcium and phosphate ions are supplied from a source external to the tooth to promote ion deposition into crystal voids in demineralized enamel to produce net mineral gain[4]. Minimum intervention as the term refers to the principle of treatment in dentistry in which early intervention minimizes tooth destruction because the disease is diagnosed prior to the destruction of the tooth. Hence it is possible to remineralize the carious lesions [5]. The principles of minimal intervention in the management of dental caries (adopted by the FDI General Assembly, 1st October, 2002, Vienna) are [6]:

- Modification of oral flora

- Patient education

- Remineralization of cavitated lesions of enamel and dentin

- Minimal intervention of cavitated lesions
- Repair of defective restorations.

Flouridated and Non-flouridated agents cause the remineralisation of the carious lesions. Flouridated agents increases caries resistance may arise from both systemic and topical applications of fluoride and can be broadly grouped as follows:

- increased enamel resistance

- increased rate of maturation

- remineralization of incipient caries

- interference with micro-organisms and improved tooth morphology[7].

\section{Ideal Requirements of Remineralizing Material}

- It Should deliver calcium and phosphate into the sub- surface

- It Should not deliver an excess of calcium

- It Should not favor calculus formation

- It Should work at an acidic pH to stop demineralization during a carious attack

- Should be able to work in xerostomic patients as saliva cannot effectively stop the carious process

- Should be able to boost the remineralizing properties of saliva

- The novel materials should be able to show some benefits over fluoride ${ }^{8}$. 

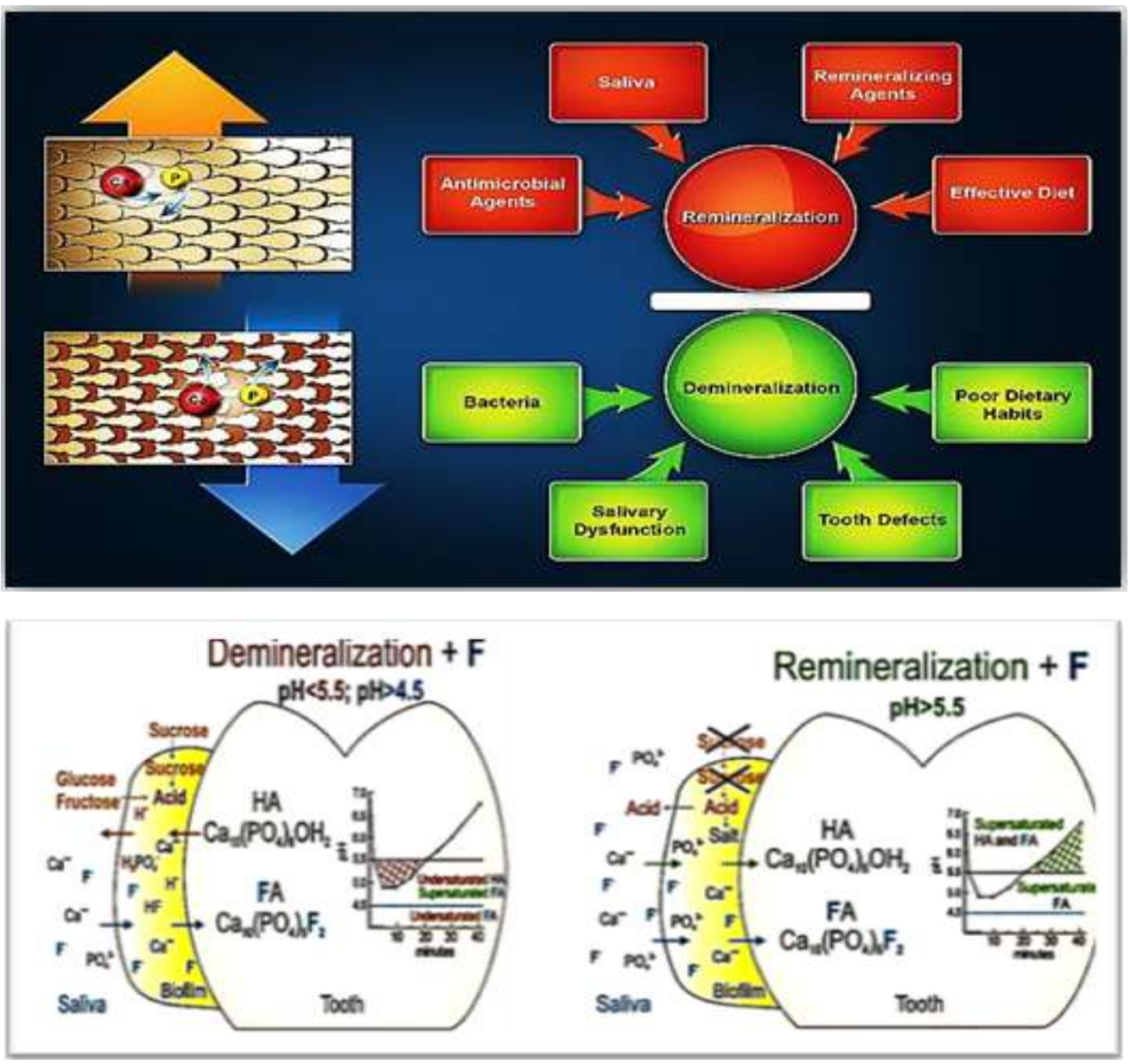

\section{Sugar Substitutes}

Consumption of diet rich in sucrose results in high caries activity. Replacing sucrose with the alternatives called as sugar subistitutes. Xylitol is a 5carbon sugar which has shown non-cariogenic and cariostatic results and its anticariogenic effects is attributable to antimicrobial action, stimulation of saliva results in increased PH. Increased salivary flow results in increased buffering capacity against acids and high mineral content will provide the minerals to remineralize the damaged areas of enamel $[9,10]$. Studies [11-13] have shown xylitol causes the net reduction in caries is by $83-99 \%$. Sorbitol stimulates saliva without causing a drop to the critical $\mathrm{PH}$. The capacities of xylitol and sorbitol to remineralize early veneer caries appear to be nearly similar [14]. Isomalt is a non-cariogenic sugar that is generally utilized as a sugar substitute. Adding isomalt to a demineralizing arrangement has appeared to fundamentally decrease tooth mineral loss [15].

\section{Fluorides}

Fluoride is known for its anti-caries effect as it promote the development of fluorapatite, which is more corrosive safe than hydroxyapatite and helps in remineralization, obstruct the ionic holding during pellicle and plaque arrangement and restraint the microbial development and metabolism[16].

\section{'Non-acidic' type}

Neutral Fluoride solutions, Fluoride tablets, Duraphat, Elmex, which have sufficient Fluoride content to react with the outer enamel and produce sufficient $\mathrm{Ca} 2+$ ions by dissolution of the solid tooth structure so that $\mathrm{CaF} 2$ and some Fluorohydroxyapatite (FAP) is precipitated.

\section{'Acidic' type}

These include acidulated phosphate fluoride solutions, Fluor Protector, some toothpastes and acidic mouth rinses. These produce $\mathrm{Ca} 2+$ by etching the enamel surface directly because of the low $\mathrm{pH}$ and precipitate $\mathrm{CaF} 2$ and $\mathrm{FAP}$ on the surface. Fluoride which is released from $\mathrm{CaF} 2$ gets precipitated on the surface of tooth and can have the following effects [17]:

(i) It increases the salivary Fluoride level.

(ii) It diffuses rapidly through permeable, mineraldeficient, micrometer size spots into the underlying enamel.

Fluoride is highly effective on smooth surface caries but it has limited effect on pit and fissure caries [18]. Although fluoride presents no problems when used properly, among certain parts of the world, there has been the suggestion that fluoride exposure should be limited [19]. Overexposure of fluoride can also cause fluorosis. All these limitations have prompted 
researchers to look for non- fluoridated alternatives for remineralization. Nordstrom and Birkhed [20], 2010 showed a superior preventive effect of a 5,000-ppm dentifrice compared with a 1,450-ppm-F dentifrice in a two-year clinical trial in adolescents. Numerous clinical trials have demonstrated the efficacy of a highconcentration fluoride varnish in high-caries-risk individuals (Autio-Gold and Courts 2001 [21], Ferreira et al. [22, 23]

\section{Tri-Calcium Phosphate or Clinpro Tooth Crème}

TCP boosts fluoride efficacy by providing the catalytic amount of calcium which coexists with fluoride in a mouth rinse or dentifrice. TCP breaks the protective barrier, is moistened by saliva as it comes in contact with the tooth and thus facilitates the availability of calcium and phosphate [11].

\section{Casein Phosphor Peptide - Amorphous Calcium Phosphate (CPP-ACP)}

Casein, a milk phosphor-protein, interacts with calcium and phosphate. It is used as CPP-ACP (casein phophopeptides with amorphous calcium phosphate) or CPP-ACFP (casein phophopeptides with amorphous calcium fluoride phosphate). As the $\mathrm{pH}$ of the material increases, the bound form of amorphous calcium phosphate increases thereby stabilizing free calcium and phosphate. CPP stabilizes the calcium and phosphate ions in dental plaque and dental enamel. CPP-ACP can restrict ACP at the tooth structure, expanding the degree of calcium phosphate in plaque and henceforth may go about as a calcium phosphate reservoir, buffering the free calcium and phosphate particle exercises, there-by CPP stabilizes ACP, thereby maintaining state of supersaturation of calcium and phosphate, reducing demineralization and increasing remineralization [24,25]. CPP also is believed to have an antibacterial and buffering effect on plaque and interfere in the growth and adherence of Streptococcus mutans and Streptococcus sorbinus. CPP-ACP fundamentally diminished caries action in a subordinate way, as $1 \%$ CPP-ACP delivered about a $55 \%$ decrease in smooth surface caries and a $46 \%$ decrease in gap caries movement, which is comparative essentially to that created by $500 \mathrm{ppm}$ of fluoride. Combined with fluoride, CPP-ACP has an additive effect on caries activity [26]. Morgan et al. in 2008 conducted 2 year in vivo study and resulted that CPP-ACP significantly slowed progression of enamel caries on proximal surfaces [27]. Similarly Rao et al in 2009, Wong RH et al. in 2010, Zalizniak et al. in 2013, Shadman et al. in 2015 did both in vivo and in vitro studies from time to time regarding $\mathrm{CPP}-\mathrm{ACP}$ and ended the study with positive results $[28,29]$. A portion of $5 \mathrm{gm}$ of CPP-ACP delivered $148 \%$ more remineralization contrasted with $2 \mathrm{gm}$ of CPP-ACP per liter of milk. It has shown anticariogenic, anti -erosive efficiency and reduces dentine hypersensitivity. It is delivered in the form of chewing gum, mouthwashes, dentifrices, and also added in various restorative materials [30].

\section{Amorphous Calcium Phosphate}

It acts as a reservoir of calcium and phosphate for dental enamel and was first described by Aaron S Posner in the mid-1960s. ACP was present in a dentifrice called Enamelon also contained unstabilised calcium and phosphorous with fluoride. This formulation delivers fluoride to the site thereby causing remineralisation of the enamel [24]. However, Unstable fluorapatite would sequester accessible fluoride particles and decrease the capacity to remineralize lacquer during corrosive test. Thus, the dependability of $\mathrm{ACP}$ is an issue [31].

\section{Bio Active Glass (Sodium Calcium Phosphosilicate)}

Bioactive glass, a biomimetic material, affects the signaling pathway, thereby restoring the tooth structure. NovaMin contains bioactive glass, and calcium sodium phosphosilicate. It has antimicrobial activity towards Steptococous mutans and Streptococcus sanguis. It aids in remineralization of tooth structure especially in patients with systemic problems. Bioglass was invented by Dr. Larry Hench in1960s. It acts as a biomimetic mineralizer matching the body's own mineralizing traits while also affecting cell signals in a way that benefits the restoration of tissue structure and function [11].

It interacts with saliva and discharges sodium, calcium, and phosphorous particles into the spit that are accessible for remineralization of the tooth surface. These particles have been appeared to discharge particles and change into HCA for as long as about fourteen days. At last, these particles will totally change into HCA [23]. Caries can also result from inadequate saliva, without which fluoride is of limited value. Thus, individuals who experience reduced calcium, phosphate and fluoride ions caused by hyposalivation can benefit from the use of bioactive glass. In addition, women are at increased caries risk due to inadequate salivary calcium levels at different points in their lives, including ovulation, pregnancy and post-menopause, resulting in the same net effect as reduced saliva fluoride efficacy. Thus, the use of bioactive glass (Novamin Technology) in remineralization of enamel is quite promising, especially in patients with systemic problems, but further research needs to be undertaken to prove its efficacy. The NovaMin Technology was created by Dr. Len Litkowski and Dr. Gary Hack. Recently available things in the market are DenShield Conditioner with NovaMin, NuCare-Prophylaxis Paste with NovaMin, and Oravive, NuCare-Root NovaMin: SootheRx [32, 33].

\section{Self-Assembling Peptide}

Recent developments in research have revealed the role of treatment with peptide where it proved a combined effect of increased mineral gain and inhibition of mineral loss from the tooth. $\beta$ sheet forming peptides P11-4 self-assembles themselves to form three-dimensional scaffolds under defined 
environmental conditions which nucleate the hydroxyapatite de novo and facilitates mineralized tissue regeneration, thus mimicking the action of enamel matrix proteins during tooth development. Single application of P11-4 is beneficial in the treatment of early caries lesions. The anionic groups of the P11-4 side chains attract $\mathrm{Ca}++$ ions, inducing the precipitation of hydroxyapetite in situ $[34,35]$.

\section{Nanomaterials}

Nanoparticles used are Calcium Fluoride Nanoparticles. Xu HHK et al. [36] have shown that the addition of nanoCaF2 increases the cumulative fluoride release compared to the fluoride release in traditional glass ionomer cements. Calcium Phosphate-based Nanomaterials includes nanoparticles of HAP, TCP, and ACP as sources to release calcium/phosphate ions and increase the supersaturation of HAP in carious lesions.

\section{Theobromine}

Theobromine is a white crystalline powder of methylxanthine family. It is seen cocoa (240 mg/cup) and chocolate (1.89\%) and it differs from caffeine by only one methyl group (1, 3, 7 dimethlyxanthine) [37]. Falster et al. [38] 1993 conducted an animal study and it was shown that pure cocoa powder prevents dental caries. An increase in the percentage of cocoa extract in the diet caused a proportionate reduction in dental caries. It was suggested that cocoa extract has an anticaries potential. Amaechi et al. [39], observed a significantly higher mineral gain with theobromine and fluoride toothpaste relative to artificial saliva. Grace Syafira et al. [40], have shown an increased enamel micro-hardness after treatment with theobromine on the enamel surface. Other materials used are Grape seed, Polydopamine and Arginine bicarbonate [41].

\section{CONCLUSION}

Demineralization and remineralization of tooth structure is a continuous process. The remineralization process can be seen in incipient carious lesions. Newer nonfluoride techniques can re-establish the health of oral tissues without adverse effects of fluorides. In current the motive of restorative dentistry has been adminstered towards conservative approach, out of which remineralization procedures are the mostly preferred. Preventing an incipient lesion from developing into a cavitated lesion will go a long way in maintaining the teeth of an individual. Since detection of carious lesions is possible at an early stage so, instead of waiting till frank cavitation, efforts should be made to remineralize the lesion in earlier stages using appropriate remineralizing agents?

\section{REFERENCES}

1. Jindal, S., Gupta, N., Gupta, P., Arora, V., \& Mehta, N. (2015). Reverse the adverse: A review. Int J Adv Health Sci, 1(10), 21-24.
2. Rao, A., \& Malhotra, N. (2011). The role of remineralizing agents in dentistry: a review. Compendium, 32(6), 27-34.

3. Choksi, K., Choksi, A., Sebastian, S.S., Zaheer, A., Mohan, S., Dhanya, R.S. (2016). Newer Nonflouride Remineralisation Agents: An Update. Int J Oral Care Res, 4(4):291- 96.

4. Cochrane, N. J., Cai, F., Huq, N. L., Burrow, M. F., \& Reynolds, E. C. (2010). New approaches to enhanced remineralization of tooth enamel. Journal of dental research, 89(11), 1187-1197.

5. Limeback, H., Lai, J. Y., Bradley, G., \& Robinson, C. (2012). A brief introduction to oral diseases: caries, periodontal disease, and oral cancer. Comprehensive Preventive Dentistry, 1.

6. Rainey, J. T. (2002). Air abrasion: an emerging standard of care in conservative operative dentistry. Dental Clinics, 46(2), 185-209.

7. Tyagi, S. P., Garg, P., Sinha, D. J., \& Singh, U. P. (2013). An update on remineralizing agents. Journal of Interdisciplinary Dentistry, 3(3), 151.

8. Walsh, L. J. (2009). Contemporary technologies for remineralization therapies: A review. Int Dent SA, 11(6), 6-16.

9. Damle, S.G. (2017). T extbook of Pediatric Dentistry. Fifth edition, 202-203.

10. Mäkinen, K. K. (2010). Sugar alcohols, caries incidence, and remineralization of caries lesions: a literature review. International journal of dentistry, 2010.

11. Reynolds, E. C. (2008). Calcium phosphate- based remineralization systems: scientific evidence?. Australian dental journal,53(3), 268273.

12. Amaechi, B. T., Higham, S. M., \& Edgar, W. M. (1998). The influence of xylitol and fluoride on dental erosion in vitro. Archives of oral biology, 43(2), 157-161.

13. Maehara, H., Iwami, Y., Mayanagi, H., \& Takahashi, N. (2005). Synergistic inhibition by combination of fluoride and xylitol on glycolysis by mutans streptococciand its biochemical mechanism. Caries Research, 39(6), 521-528.

14. Suda, R., Suzuki, T., Takiguchi, R., Egawa, K., Sano, T., \& Hasegawa, K. (2006). The effect of adding calcium lactate to xylitol chewing gum on remineralization of enamel lesions. Caries research, 40(1), 43-46.

15. Manning, R. H., Edgar, W. M., \& Agalamanyi, E. A. (1992). Effects of chewing gums sweetened with sorbitol or a sorbitol/xylitol mixture on the remineralisation of human enamel lesions in situ. Caries research, 26(2), 104-109.

16. Niessen, L. C., \& Gibson, G. (1997). Oral health for a lifetime: Preventive strategies for the older adult. Quintessence International, 28(9), 626.

17. Mellberg, J. R., \& Ripa, L. W. (1983). Fluoride in preventive dentistry: theory and clinical applications. Quintessence Pub Co. 
18. Reynolds, E. C., Cai, F., Cochrane, N. J., Shen, P., Walker, G. D., Morgan, M. V., \& Reynolds, C. (2008). Fluoride and casein phosphopeptideamorphous calcium phosphate. Journal of Dental Research, 87(4), 344-348.

19. Brown, W. E. (1974). Physicochemical mechanisms of dental caries. Journal of dental research, 53(2), 204-216.

20. Nordström, A., \& Birkhed, D. (2010). Preventive effect of high-fluoride dentifrice $(5,000 \mathrm{ppm})$ in caries-active adolescents: a 2-year clinical trial. Caries research, 44(3), 323-331.

21. Autio-Gold, J. T., \& Courts, F. (2001). Assessing the effect of fluoride varnish on early enamel carious lesions in the primary dentition. The Journal of the American Dental Association, 132(9), 1247-1253.

22. Ferreira, J. M. S., Aragão, A. K. R., Rosa, A. D. B., Sampaio, F. C., \& Menezes, V. A. D. (2009). Therapeutic effect of two fluoride varnishes on white spot lesions: a randomized clinical trial. Brazilian oral research, 23(4), 446-451.

23. Du, M., Cheng, N., Tai, B., Jiang, H., Li, J., \& Bian, Z. (2012). Randomized controlled trial on fluoride varnish application for treatment of white spot lesion after fixed orthodontic treatment. Clinical oral investigations, 16(2), 463468.

24. Karlinsey, R. L., \& Mackey, A. C. (2009). Solidstate preparation and dental application of an organically modified calcium phosphate. Journal of materials science, 44(1), 346-349.

25. Gagnaire, V., Pierre, A., Molle, D., \& Leonil, J. (1996). Phosphopeptides interacting with colloidal calcium phosphate isolated by tryptic hydrolysis of bovine casein micelles. Journal of Dairy Research, 63(3), 405-422.

26. Reynolds, E. C., Cain, C. J., Webber, E. L., Black, C. L., Riley, P. F., Johnson, I. H., \& Perich, J. W. (1995). Anticariogenicity of calcium phosphate complexes of tryptic casein phosphopeptides in the rat. Journal of Dental Research, 74(6), 1272-1279.

27. Morgan, M. V., Adams, G. G., Bailey, D. L., Tsao, C. E., Fischman, S. L., \& Reynolds, E. C. (2008). The anticariogenic effect of sugar-free gum containing CPP-ACP nanocomplexes on approximal caries determined using digital bitewing radiography. Caries Research, 42(3), 171184.

28. Shadman, N., Ebrahimi, S. F., Shoul, M. A., \& Sattari, H. (2015). In vitro evaluation of casein phosphopeptide-amorphous calcium phosphate effect on the shear bond strength of dental adhesives to enamel. Dental research journal, 12(2), 167.

29. Divyapriya, G. K., Yavagal, P. C., \& Veeresh, D. J. (2016). Casein phosphopeptide-amorphous calcium phosphate in dentistry: An update. International Journal of Oral Health Sciences, 6(1), 18.

30. Walsh, L. J. (2009). The current status of tooth crèmes for enamel remineralization. Dental Inc, 2(6), 38-42.

31. Burwell, A., Jennings, D., \& Greenspan, D. C. (2010). NovaMin and dentin hypersensitivity--in vitro evidence of efficacy. The Journal of clinical dentistry, 21(3), 66-71.

32. Tai, B. J., Bian, Z., Jiang, H., Greenspan, D. C., Zhong, J., Clark, A. E., \& Du, M. Q. (2006). Antigingivitis effect of a dentifrice containing bioactive glass (NovaMin®) particulate. Journal of clinical periodontology, 33(2), 86-91.

33. Iijima, Y., Cai, F., Shen, P., Walker, G., Reynolds, C., \& Reynolds, E. C. (2004). Acid resistance of enamel subsurface lesions remineralized by a sugar-free chewing gum containing casein phosphopeptide-amorphous calcium phosphate. Caries Research, 38(6), 551-556.

34. Tyagi, S. P., Garg, P., Sinha, D. J., \& Singh, U. P. (2013). An update on remineralizing agents. Journal of Interdisciplinary Dentistry, 3(3), 151.

35. Amaechi, B. T. (2015). Remineralization therapies for initial caries lesions. Current Oral Health Reports, 2(2), 95-101.

36. Zhang, X., Deng, X., \& Wu, Y. (2015). Remineralizing Nanomaterials for Minimally Invasive Dentistry. In Nanotechnology in Endodontics (pp. 173-193). Springer, Cham.

37. Falster, A. U., Yoshino, S., Hashimoto, K., Joseph Jr, F., Simmons, W. B., \& Nakamoto, T. (1993). The effect of prenatal caffeine exposure on the enamel surface of the first molars of newborn rats. Archives of oral biology, 38(5), 441-447.

38. Amaechi, B. T., Porteous, N., Ramalingam, K., Mensinkai, P. K., Vasquez, R. C., Sadeghpour, A., \& Nakamoto, T. (2013). Remineralization of artificial enamel lesions by theobromine. Caries Research, 47(5), 399-405.

39. Syafira, G., Permatasari, R., \& Wardani, N. (2013). Theobromine effects on enamel surface microhardness: in vitro. Journal of Dentistry Indonesia, 19(2), 32-36.

40. Epasinghe, D. J., Yiu, C. K. Y., \& Burrow, M. F. (2015). Synergistic effect of proanthocyanidin and CPP- ACFP on remineralization of artificial root caries. Australian dental journal, 60(4), 463-470.

41. Zhou, Y. Z., Cao, Y., Liu, W., Chu, C. H., \& Li, Q. L. (2012). Polydopamine-induced tooth remineralization. ACS applied materials \& interfaces, 4(12), 6901-6910.

42. Cheng, X., Xu, P., Zhou, X., Deng, M., Cheng, L., Li, M., .. \& Xu, X. (2015). Arginine promotes fluoride uptake into artificial carious lesions in vitro. Australian Dental Journal, 60(1), 104-111. 